\title{
IPC training in Sierra Leone- ICAN's role in fighting Ebola
}

\author{
S Mehtar*, B Hakizimana, Infection Control Africa Network Education and Training Working Group \\ From 3rd International Conference on Prevention and Infection Control (ICPIC 2015) \\ Geneva, Switzerland. 16-19 June 2015
}

\section{Introduction}

Thousands of people have been affected by Ebola; the crude mortailty rate is estimated at around 53\%. Responding to WHO, the Infection Control Africa Network (ICAN) has been at the forefront of fighting Ebola since April 2015. Two training courses were presented between February and mid March 2015 in Sierra Leone funded by the WHO \& CDC.

\section{Objectives}

The training was to ensure that evidence based IPC practices were put in place to counteract rituals, myths and superstition which surrounded the community and healthcare workers (HCW) with increasing spread of Ebola; to clear the confusion created by the several organisations teaching different methods of IPC.

\section{Methods}

The Basic Ebola IPC course registered at Stellenbosch University, was delivered to 60 and 75 students for the $\mathrm{WHO}$ and CDC respectively. A pre and post assessment examination measured the level of knowledge gained. Didactic lectures were delivered in the morning and practical work in the afternoon. The WHO guidelines on Ebola were used as a basis for training these HCW to function at National and District level.

A two week course was CDC funded. The first week was the Ebola IPC course, the second was CDC material based on the National SOP for Ebola IPC in Sierra Leone to train the trainers. Presentation to their peers were marked for presentation, content, clarity, material, time keeping and scientific content.

Both the training programmes were anonymously evaluated by the students each day.

\section{Results}

Both groups were experienced but needed support. The average increase between pre and post test knowledge was $27 \%$ for both sets of students; starting at $37 \%$ post test average was $87 \%$. An increased level of confidence, presentation/ communication skills was $32 \%$. By the end, evidence and risk assessment were driving their decision making. Course evaluation averaged between $87 \%$ and $92 \%$.

\section{Conclusion}

The training provided by ICAN funded by the WHO and CDC had a major impact on the outcome of IPC in Sierra Leone. The students are confident in dealing with Ebola, carrying out appropriate risk assessments and protecting themselves, their colleagues and their patients.

\section{Disclosure of interest \\ None declared.}

Published: 16 June 2015

doi:10.1186/2047-2994-4-S1-012

Cite this article as: Mehtar et al:: IPC training in Sierra Leone- ICAN's

role in fighting Ebola. Antimicrobial Resistance and Infection Control 2015 4(Suppl 1):012. 